\title{
Pemanas Listrik Menggunakan Prinsip Induksi Elektromagnetik
}

\author{
Lukas B. Setyawan ${ }^{1}$, Deddy Susilo², Amsal Victory Wicaksono ${ }^{3}$ \\ Program Studi Teknik Elektro, \\ Fakultas Teknik Elektronika dan Komputer, \\ Universitas Kristen Satya Wacana, Salatiga \\ 1lukas.setyawan@staff.uksw.edu, 2deddy.susilo@staff.uksw.edu, \\ 3612009056@student.uksw.edu
}

\begin{abstract}
Ringkasan
Pemanas listrik ini menggunakan prinsip induksi elektromagnetik. Induksi elektromagnetik akan memanaskan panci yang diletakkan di atas pemanas dengan alas terbuat dari bahan kaca tebal. Pemanas ini tidak mengeluarkan api dan alas pemanas tidak panas sehingga aman bagi pengguna serta terhindar dari kemungkinan terjadi kebakaran. Panci yang digunakan untuk memasak harus terbuat dari logam ferromagnetik. Tersedia 3 pilihan mode memasak, yaitu FAST, NORMAL, dan SLOW. Pada mode FAST, kompor induksi ini dapat memasak air dengan volume $330 \mathrm{ml}$ dalam waktu 36 sekon. Sumber daya pemanas induksi ini adalah jala-jala listrik 220 volt AC.
\end{abstract}

Kata kunci: pemanas induksi, panci ferromagnetik, induksi elektromagnetik

\section{Pendahuluan}

Pemakaian kompor konvensional seringkali menyebabkan terjadinya kebakaran atau kecelakaan kerja yang ditimbulkan oleh api kompor. Dengan pemanas induksi resiko terjadi kebakaran dan kecelakaan kerja yang ditimbulkan oleh api kompor bisa dihilangkan. Hal ini bisa terjadi karena pemanas induksi tidak mengeluarkan api. Untuk memasak digunakan panci yang terbuat dari logam ferromagnetik. Saat memasak alas pemanas yang terbuat dari bahan kaca tebal tidak panas sehingga aman bagi pengguna. Permukaan alas pemanas rata sehingga mudah dibersihkan dari tumpahan.

Pembahasan makalah ini dimulai dengan penjelasan sistem pemanas induksi meliputi proses kerja sistem, sistem perangkat keras, dan sistem perangkat lunak. Kemudian dilanjutkan dengan hasil pengujian dan diakhiri dengan kesimpulan.

\section{Sistem Pemanas Induksi}

Sistem pemanas induksi memiliki bagan kotak seperti Gambar 1. Sistem ini tersusun dari Sumber Tegangan 220 VAC, Penyearah, Tapis, Konverter DC ke AC, Kontrol, dan Kumparan. Sketsa pemanas induksi digambarkan pada Gambar 2. Sedangkan foto pemanas induksi dipaparkan di Gambar 3.

Panci berbahan logam ferromagnetik untuk memasak diletakkan di atas alas pemanas yang terbuat dari kaca tebal. 
Tersedia fasilitas untuk memilih mode memasak lewat tombol FAST, NORMAL, dan SLOW. Tampilan menu digunakan LCD.

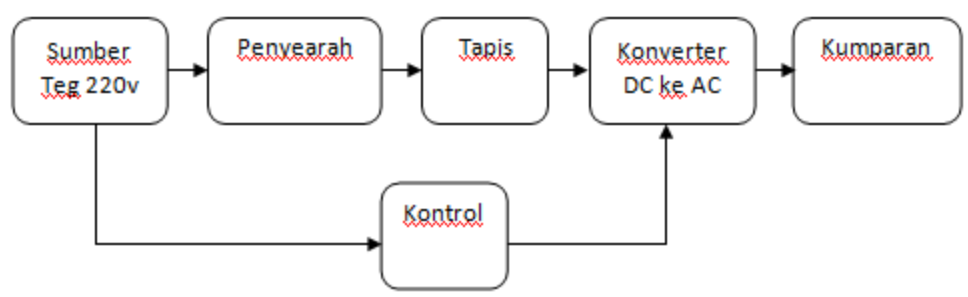

Gambar 1. Bagan kotak pemanas induksi

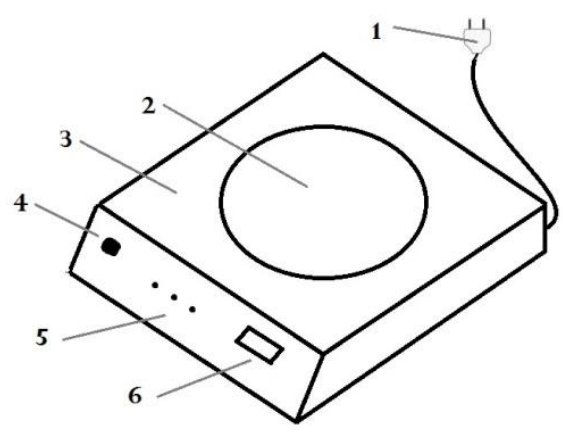

$$
\begin{array}{ll}
\text { Keterangan: } \\
\text { 1. } & \text { AC plug } \\
\text { 2. } & \text { Alas pemanas (kaca tebal) } \\
\text { 3. } & \text { Badan pemanas induksi (akrilik) } \\
\text { 4. } & \text { Tombol START } \\
\text { 5. } & \text { Tombol pilihan mode } \\
\text { 6. } & \text { Penampil LCD (Liquid Crystal Display) }
\end{array}
$$

Gambar 2. Sketsa pemanas induksi

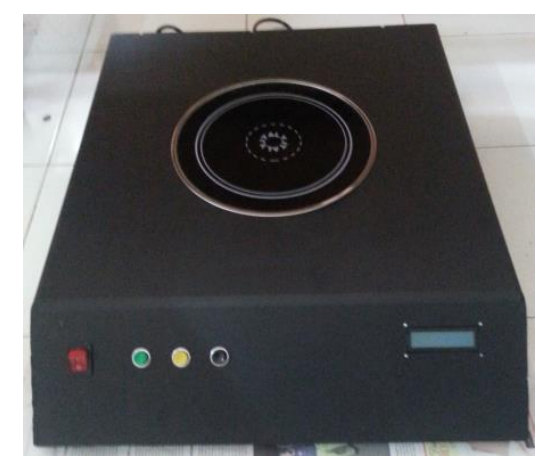

Gambar 3. Foto dari pemanas induksi

\subsection{Proses Kerja Sistem}

Prinsip sistem pemanas induksi adalah memberikan induksi elektromagnetik pada panci logam ferromagnetik yang diletakkan di atas alas pemanas. Induksi elektromagnetik diberikan dengan frekuensi $20 \mathrm{kHz}$ dan duty cycle $50 \%$. Sumber induksi adalah untai resonans yang terdiri dari induktor (kumparan) diparalel dengan kapasitor. Kumparan yang digunakan adalah jenis flat spiral coil seperti pada Gambar 4. Induksi elektromagnetik ini akan mengenai panci sehingga terjadi efek kulit (skin effect) yang membangkitkan arus pusar (eddy current) pada permukaan panci sehingga panci menjadi panas. 


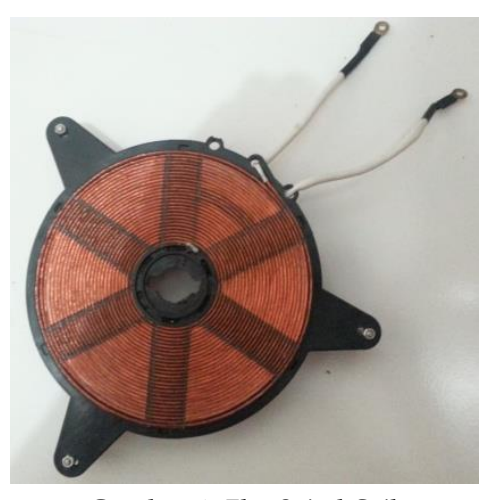

Gambar 4. Flat Spiral Coil

\subsection{Sistem Perangkat Keras}

Perangkat keras terdiri atas dua bagian, yaitu untai utama seperti Gambar 5 dan modul mikrokontroler yang bertugas untuk mengatur sistem pemanas induksi dan sebagai pembangkit sinyal PWM (Pulse Width Modultaion) dengan duty cycle 50\%.

Modul mikrokontroler menggunakan Atmega 8535 seperti Gambar 6. Tabel 1 memuat rincian pin mikrokontroler yang terhubung dengan masukan dan keluaran.

Pada mode SLOW, mikrokontroler membangkitkan sinyal PWM dengan frekuensi 15 kHz. Untuk pilihan mode NORMAL, sinyal PWM memiliki frekuensi 17,5 kHz. Sedangkan pada mode FAST, frekuensi sinyal PWM sebesar $20 \mathrm{kHz}$.

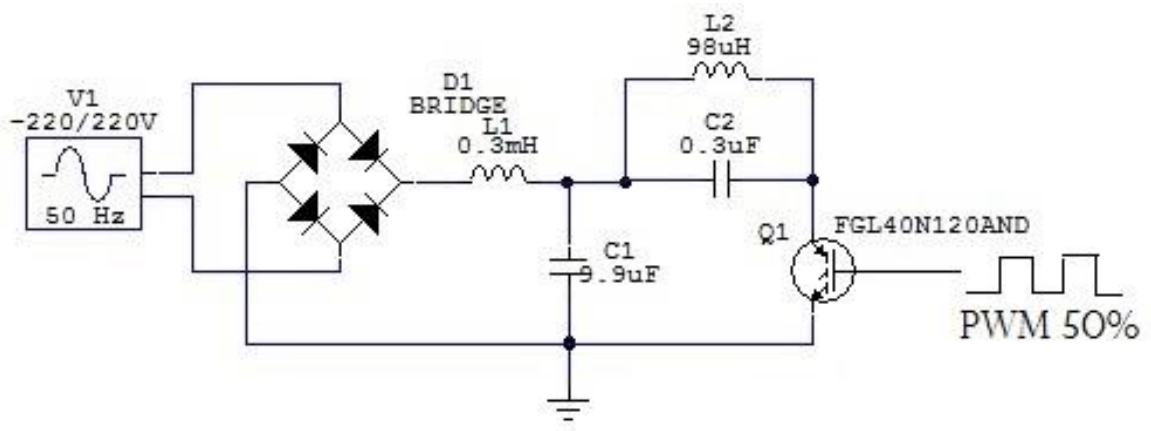

Gambar 5. Skema pemanas induksi 


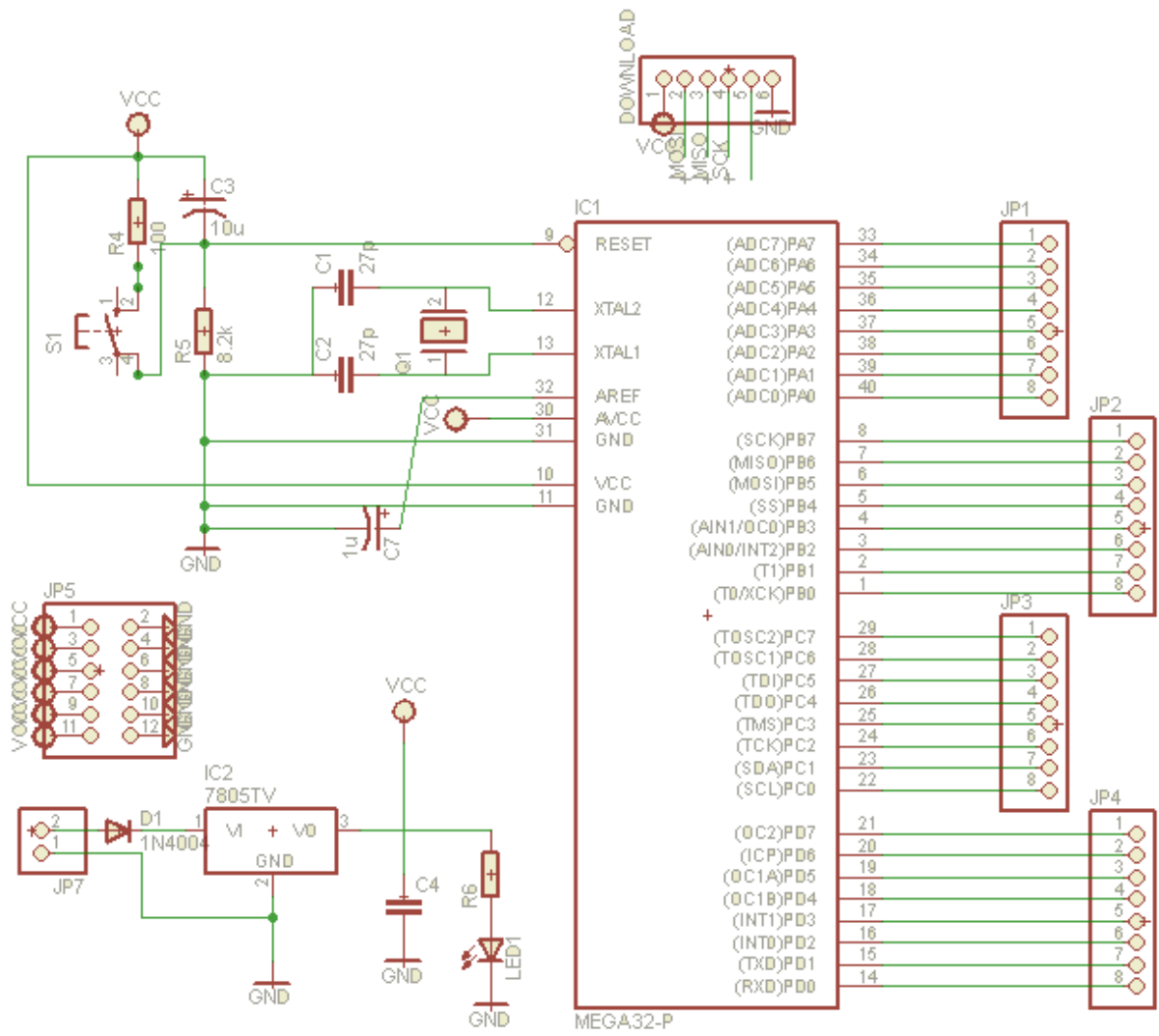

Gambar 6. Skema modul mikrokontroler

Tabel 1. Fungsi pin mikrokontroler

\begin{tabular}{|c|c|}
\hline Pin Mikrokontroler & Fungsi \\
\hline PA0 & Output Data ke LCD \\
\hline PA1 & Output Data ke LCD \\
\hline PA2 & Output Data ke LCD \\
\hline PA3 & Output Data ke LCD \\
\hline PA4 & Output Data ke LCD \\
\hline PA5 & Output Data ke LCD \\
\hline PA6 & Output Data ke LCD \\
\hline PA7 & Output Data ke LCD \\
\hline PB0 & Input dari Thermocouple \\
\hline PC0 & Input dari tombol FAST \\
\hline PC1 & Input dari tombol NORMAL \\
\hline PC2 & Input dari tombol SLOW \\
\hline PD5 & Output PWM ke Anoda TLP 250 \\
\hline & \multicolumn{2}{|}{}
\end{tabular}

\subsection{Sistem Perangkat Lunak}

Sistem perangkat lunak ditanam di dalam mikrokontroler Atmega 8535 yang akan mengatur kerja sistem dan membangkitkan sinyal PWM. Bagan alir perangkat lunak dipaparkan pada Gambar 8.

Tampilan awal pada penampil LCD seperti Gambar 7. Pengguna dapat memilih mode SLOW, NORMAL, atau FAST dengan menekan tombol yang sesuai. 


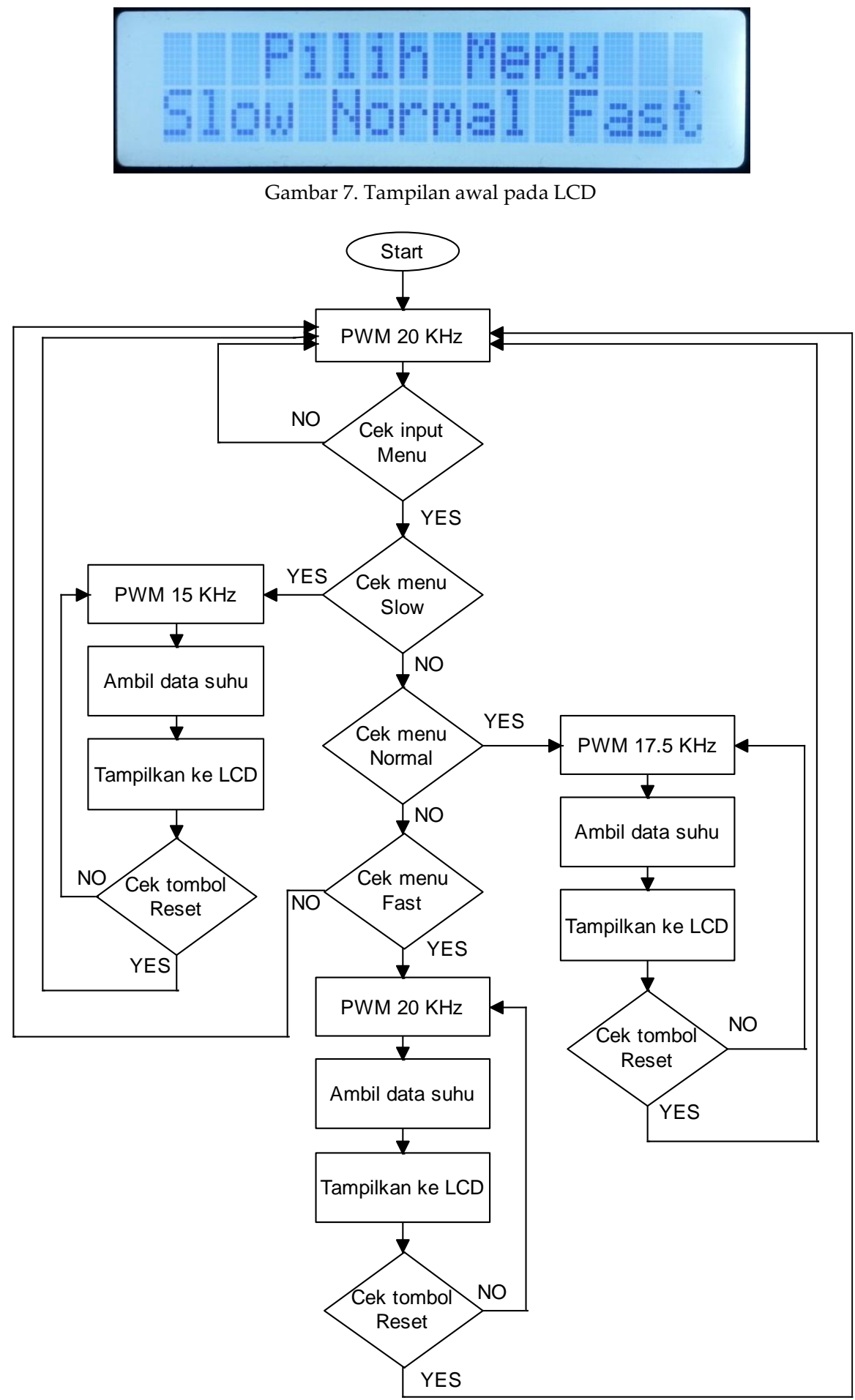

Gambar 8. Bagan alir perangkat lunak kompor induksi

\section{Hasil Pengujian}

Pengujian sistem pemanas induksi dilakukan dengan cara memanaskan air sebanyak $330 \mathrm{ml}$ mulai dari temperatur kamar hingga temperatur air mencapai $55{ }^{\circ} \mathrm{C}$. Waktu yang diperlukan dicatat menggunakan stopwatch. Pengujian dilakukan untuk 3 macam mode, yaitu SLOW, NORMAL, dan FAST. Hasil pengujian dinyatakan dalam Tabel 2. 
Pengujian berikutnya adalah membandingkan hasil pengujian sistem pemanas induksi dengan kompor listrik Maspion S-302 600W dan kompor gas Sanyo. Pada saat pengujian, kompor listrik dan kompor gas diatur pada kondisi pemanasan maksimal. Hasil pengujian seperti Tabel 3.

Tabel 2. Waktu yang diperlukan pemanas induksi untuk memanaskan air $330 \mathrm{ml}$ sampai 55 oC

\begin{tabular}{|c|c|}
\hline Mode & Waktu \\
\hline \hline SLOW & 55 sekon \\
\hline NORMAL & 46 sekon \\
\hline FAST & 36 sekon \\
\hline
\end{tabular}

Tabel 2. Waktu yang diperlukan kompor listrik dan kompor gas untuk memanaskan air $330 \mathrm{ml}$ sampai 55 oC

\begin{tabular}{|c|c|}
\hline Jenis Kompor & Waktu \\
\hline \hline Kompor listrik (Maspion S-302 600W) & 360 sekon \\
\hline Kompor gas (Sanyo) & 90 sekon \\
\hline
\end{tabular}

\section{Kesimpulan}

Sistem pemanas induksi telah berhasil direalisasikan untuk memanaskan air. Untuk memanaskan air sebanyak $330 \mathrm{ml}$ dari temperatur kamar sampai temperatur air mencapai $55{ }^{\circ} \mathrm{C}$ dibutuhkan waktu 55 sekon pada mode SLOW, 46 sekon pada mode NORMAL, dan pada mode FAST 36 sekon.

Waktu pemanasan pemanas induksi lebih cepat dibandingkan kompor listrik dan kompor gas.

Panci yang dipakai sebagai wadah untuk memasak harus terbuat dari logam ferromagnetik.

\section{Daftar Pustaka}

[1] A. Panobo, Pemanfaatan Arus Pusar Sebagai Sumber Panas Pada Pemanas Elektrik, Salatiga: Fakultas Teknik Elektronika dan Komputer, Universitas Kristen Satya Wacana, 2009.

[2] A.V. Wicaksono, Perancangan Kompor Listrik Menggunakan Teknologi Induksi Elektromagnetik, Salatiga: Fakultas Teknik Elektronika dan Komputer, Universitas Kristen Satya Wacana, 2014. 